\title{
INCREASE OF SERVICE PROPERTIES OF ELECTRIC-ARC AND PLASMA COATINGS BY USE OF ELECTRIC-PULSE EFFECT ON DOUBLE-PHASE HIGH-TEMPERATURE FLOW
}

\author{
A.N. DUBOVOJ, A.A. KARPECHENKO and M.N. BOBROV \\ Admiral Makarov National Shipbuilding University \\ 9 Geroev Stalingrada Ave., 54025, Nikolaev. E-mail: welding@nuos.edu.ua
}

\begin{abstract}
There are publications on increase of physical-mechanical properties of coatings by means of modulation of plasma arc and using of additional sources of electric field intensity. The work studies an influence of electric and pulse effect on double-phase high-temperature flow (DHTF), and, as a result, on structure and service properties of electric-arc and plasma coatings. Relationship of amplitude-frequency characteristics of high-voltage electric pulses with microstructure and properties of obtained coatings was investigated. It is shown that electric-pulse effect promotes for reduction of metal drops in DHTF and provides denser structure of plasma powder of PG-19M-01 grade and electric-arc coating from wire Sv-08G2S. 18-30\% rise of adhesion strength, 20-35\% of hardness and 1.7 times increase of wear resistance are observed. 8 Ref., 3 Tables, 5 Figures.
\end{abstract}

Keywords: thermal coatings, electric pulse, hardness, wear resistance, adhesion strength

Development of technologies for strengthening and reconditioning of machine parts and their assemblies is still relevant problem, which is manly solved at current stage of development of science and technology by deposition of functional coatings using the methods of thermal spraying (TS). In recent time, plasma and electric-arc methods receive more and more attention among TS methods. The plasma method is characterized by ability of deposition of coatings from refractory materials as well as versatile. Interest to electric-arc spraying is explained by high method efficiency, manufacturability and low cost. However, both methods have disadvantages, namely high porosity level (from 6 to $12 \%$ ) and low adhesion strength (to $30 \mathrm{MPa}$ for electric-arc coatings and to $50 \mathrm{MPa}$ for plasma ones). Additional technological operations, i.e. surface melting, electromechanical treatment, soaking etc. are used for increase of physical-mechanical properties of thermal coatings. This results in rise of coating cost due to increase of energy-consumption, usage of additional materials and development of new devices.

It is known fact that rise of physical-mechanical properties of plasma coatings can be provided by pile-up of short pulses on direct current of plasma arc. Thus, works [1,2] show that plasmatron during arc modulation is transformed in a source of shock waves, which interact with spray particles on spraying distance. This interaction results in refining and acceleration of particles, that provides for increase of physical-mechanical properties of obtained coatings. Wellknown works [3, 4] are dedicated to plasma spraying using additional source of electric field intensity. According to performed investigations, the conclusions were made on positive influence of given effect on particle rate and coating adhesion strength.

Aim of the present work lies in investigation of effect of electric-pulse effect on double-phase high-temperature flow (DHTF) and, as a result, on structure and service properties of electric-arc and plasma coatings.

Electric-arc coatings from Sv-08G2S grade wire and plasma coatings from PG-19M-01 grade powder were selected as object for investigation. Electric-arc coatings were deposited on KMD-2 machine by EM-14M spraying element using the following mode: arc voltage $25 \mathrm{~V}$, amperage $110 \mathrm{~A}$, pressure of compressed air $0.6 \mathrm{MPa}$, spraying distance $100 \mathrm{~mm}$. Plasma coatings were made on «Kiev-7» machine, equipped by PUN-1 plasmatron at following mode: arc voltage $180 \mathrm{~V}$, amperage $150 \mathrm{~A}$, spraying distance $180 \mathrm{~mm}$, consumption of plasma gas $6.5 \mathrm{~m}^{3} / \mathrm{h}$, pressure of transporting gas $0.01 \mathrm{MPa}$. Compressed air was used as plasma and transporting gases. Coating hardness was measured using Vickers type device at $5 \mathrm{~kg}$ loading on indenter. Metallographic examinations were carried out on optic microscope 
Table 1. Interval of variations and levels of factors at experiment planning for electric-arc and plasma spraying with electric-pulse effect

\begin{tabular}{||l|c|c|}
\hline \multicolumn{1}{|c|}{ Factor } & Frequency, kHz & Voltage, $\mathrm{kV}$ \\
\hline Coded designation & $X_{1}$ & $X_{2}$ \\
\hline Zero level $X_{i 0}$ & 6 & 7.5 \\
\hline Variation interval $\Delta X$ & 2 & 2.5 \\
\hline Low $X_{i}$ level & 4 & 5 \\
\hline Upper $X_{i}$ level & 8 & 10 \\
\hline
\end{tabular}

MMU-3. Coating wear resistance was determined using friction machine SMTs-2, coatingto-base adhesion strength was evaluated by tensile machine UMM-5.

Source of high-voltage electric pulses, directly connected to spraying element, was used for providing of electric-pulse effect on DHTF. Preliminary experiments showed that application of frequencies up to $4 \mathrm{kHz}$ and voltages to $5 \mathrm{kV}$ have no significant effect on strength properties of the coatings and porosity, therefore corresponding ranges of frequency and intensity of electric pulses (Table 1) were selected for experiment planning.

A method of full factorial experiment of $2^{\mathrm{k}}$ type was used for determination of optimum parameters of electric-arc effect on DHTF. Coating hardness was taken as optimizing parameter. Frequency and voltage was selected as variable factors. Such factors as current, voltage, spraying distance etc. were registered at indicated modes. Each mode was used for spraying of five speci- mens, then they were polished to $1 \mathrm{~mm}$ coating thickness and their hardness $H V 5$ was measured.

Tables 2 and 3 give a plan of full factorial experiment and its results.

Regression coefficients were calculated based on statistically processed experimental data, the checks were performed on their importance and adequacy of received models to real process of spraying of electric-arc and plasma coatings on known procedures [5]. The following regression equations were received as a result of mentioned above:

- for electric-arc spraying: $Y=2352+171 X_{1}+$ $+45 X_{2}-65 X_{1} X_{2}$

- for plasma spraying: $Y=1342+62 X_{1}+$ $+24 X_{2}-16 X_{1} X_{2}$.

Built models were used for optimizing of parameters of electric-pulse effect on DHTF by steepest ascent method. The maximum value of hardness for electric-arc spraying was obtained at $6.5 \mathrm{kHz}$, and at $5 \mathrm{kHz}$ for plasma one. Voltage value made $5 \mathrm{kV}$. Analysis of microstructures (Figure 1) indicate that application of electricpulse effect on DHTF results in refinement of coating structural elements as well as reduction of porosity from 6 to $3 \%$ for electric-arc coatings and from 6 to $2 \%$ for plasma ones, at that coating hardness increased per 35 and $20 \%$, respectively.

Size range of spray particles was determined by metallographic method using samples, collected during spraying in water. Images of microstructures were received using digital camera Delta Optic HDCE-20C, equipped with Scope

Table 2. Plan and results of experiments for electric-arc coatings from wire Sv-08G2S

\begin{tabular}{||c|c|c|c|c|c|c|c|c|c|c|}
\hline \hline \multicolumn{3}{|c|}{ Coded value of factors } & \multicolumn{5}{c|}{ Response function, MPa } & \multicolumn{2}{c|}{ Root-mean- } \\
square \\
deviation, \\
MPa
\end{tabular}

Table 3. Plan and results of experiments for electric-arc coatings from powder PG-19M-01

\begin{tabular}{|c|c|c|c|c|c|c|c|c|c|c|}
\hline \multicolumn{4}{|c|}{ Coded value of factors } & \multicolumn{5}{|c|}{ Response function, $\mathrm{MPa}$} & \multirow{2}{*}{$Y_{i}, \mathrm{MPa}$} & \multirow{2}{*}{$\begin{array}{l}\text { Root-mean- } \\
\text { square } \\
\text { deviation, } \\
\mathrm{MPa}\end{array}$} \\
\hline$X_{0}$ & $X_{1}$ & $X_{2}$ & $X_{12}$ & $Y_{1}$ & $Y_{2}$ & $Y_{3}$ & $Y_{4}$ & $Y_{5}$ & & \\
\hline+ & - & - & + & 1330 & 1372 & 1390 & 1400 & 1330 & 1364 & 29.5 \\
\hline+ & - & + & - & 1470 & 1430 & 1450 & 1450 & 1415 & 1443 & 18.9 \\
\hline+ & + & - & - & 1230 & 1270 & 1270 & 1320 & 1270 & 1272 & 28.6 \\
\hline+ & + & + & + & 1290 & 1280 & 1320 & 1294 & 1254 & 1288 & 21.4 \\
\hline
\end{tabular}



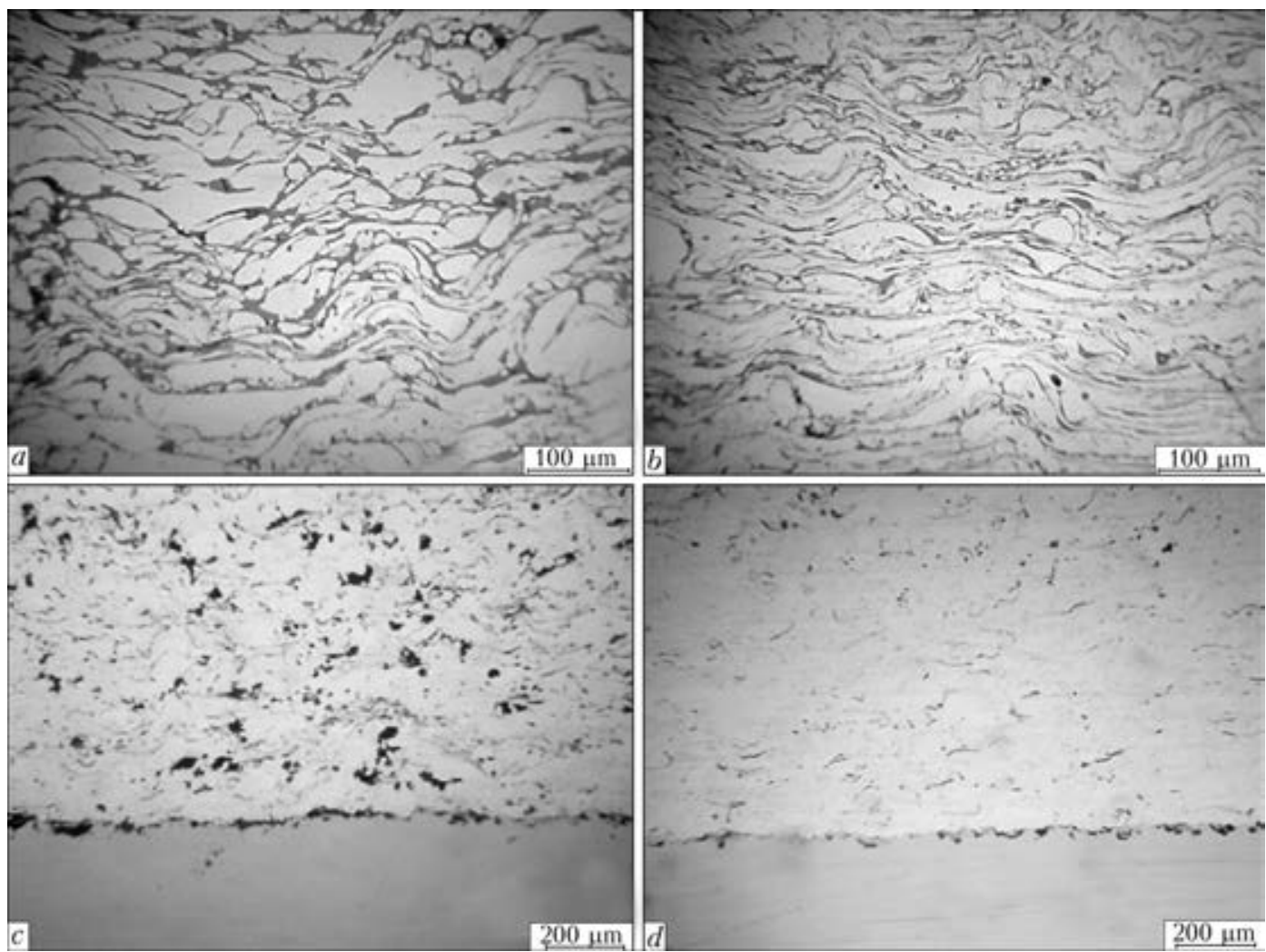

Figure 1. Microstructure of coatings: $a$ - electric-arc coating produced by traditional technology; $b-$ electric-arc coating deposited using electric-pulse effect $(6.5 \mathrm{kHz}, 5 \mathrm{kV}) ; c-$ plasma coating produced by traditional technology; $d$ - plasma coating deposited using electric-pulse effect $(6.5 \mathrm{kHz}, 5 \mathrm{kV})$

Image 9.0 software. Obtained images were analyzed in software metallographic complex MEGRAN. Five samples each, including around 1000 particles, were analyzed in general. Examination results, given in Figure 2, showed that application of electric-pulse effect of optimum mode provides for additional fragmentation of particles in double-phase flow.

Molten metal drops disperse as a result of aerodynamic effect of gas jet in plasma as well as electric-arc spraying. At that, dispersion of

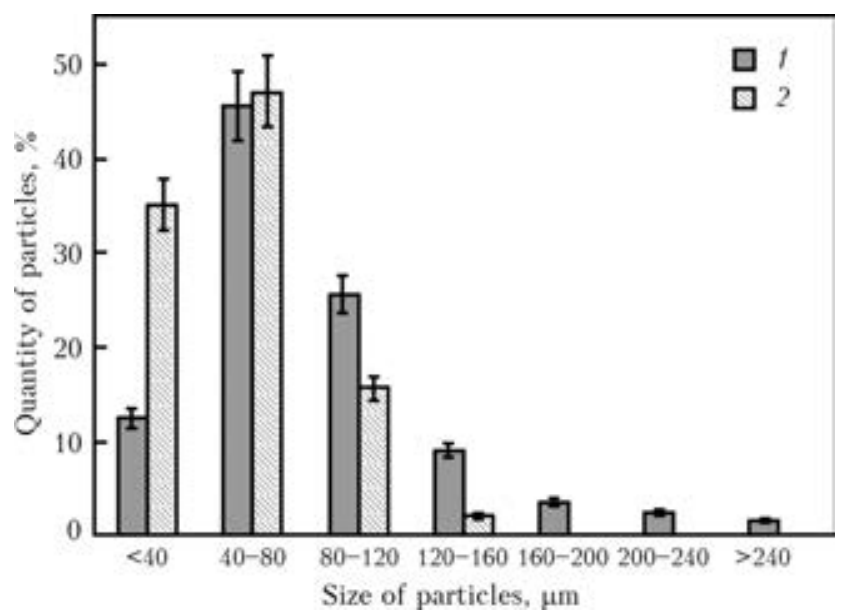

Figure 2. Fractional composition of particles in electricarc spraying: 1 - spraying was carried out using traditional technology; 2 - using electric-pulse effect at optimum mode liquid drop takes place only at reaching of critical droplet diameter, and drop decomposition is impossible at lower size. Further fragmentation of molten drop is possible in two ways in use of additional pile-up of electric pulses on DHTF. The first one is explained by appearance of nonself-maintaining gas discharge in piling-up of pulse potential difference over the spraying distance. The gas discharge is accompanied by ap-

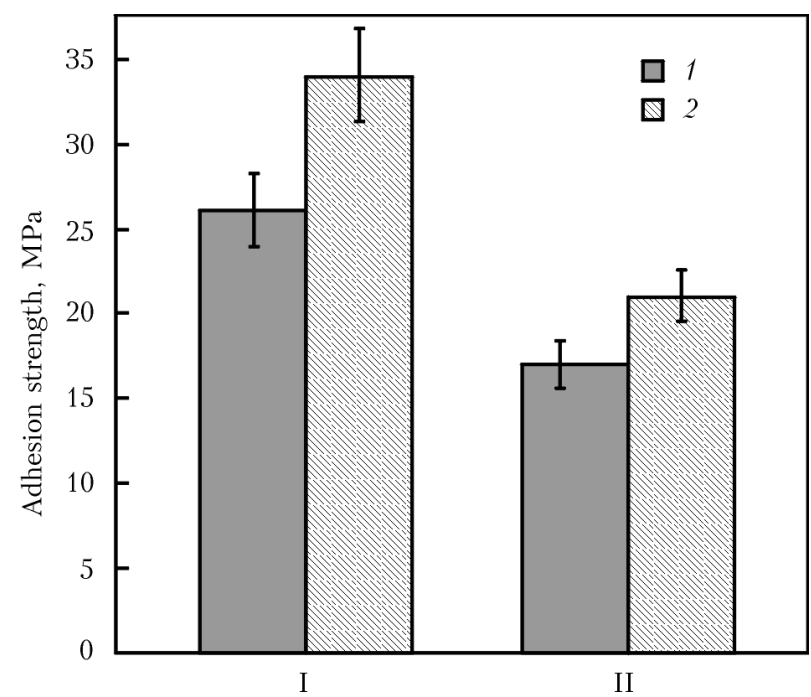

Figure 3. Results of determination of adhesion strength of electric-arc (I) and plasma coatings (II): 1 - spraying was carried out using traditional technology; 2 - using electric-pulse effect at optimum mode 

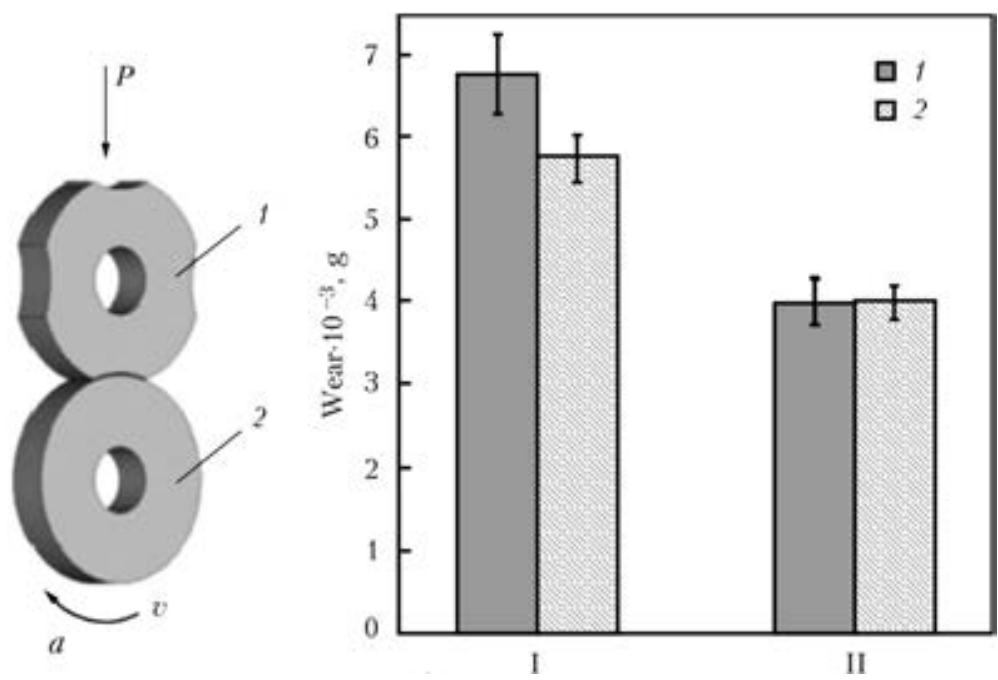

Figure 4. Wear resistance of electric-arc coatings: $a-$ scheme of wear resistance testing $(1-$ shoe; $2-$ roller $)$; $b-$ results of wear resistance testing: I - without pile-up of electric pulses; II - with pile-up of high-voltage electric pulses of $6.5 \mathrm{kHz}$ and $5 \mathrm{kV}(1-$ coating; 2 - shoe $)$

pearance of shock waves, which provide additional dispersion of liquid drops in high-temperature flow. The second one is related with acquiring of additional charge by liquid particles, which results in reduction of their surface tension and particle decomposition due to appearance of Coulomb repulsive forces in alternating electric

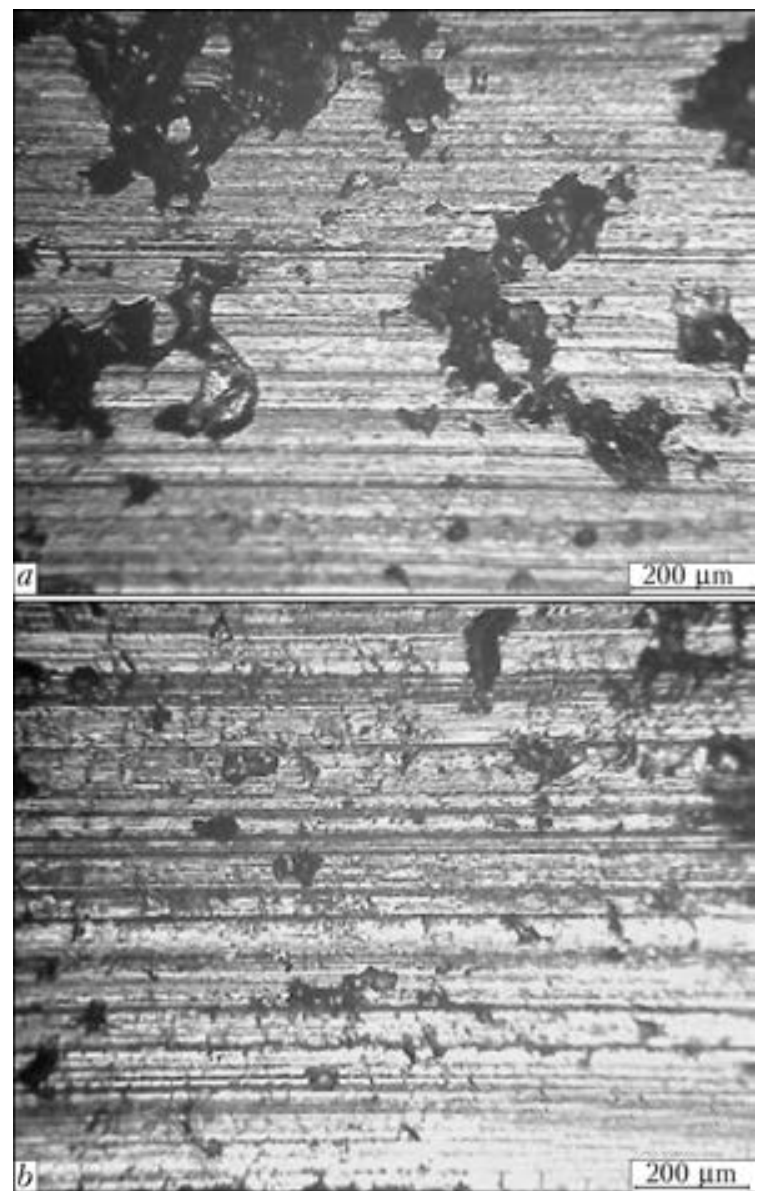

Figure 5. Microstructure of friction surface of sprayed roller: $a$ - spraying by traditional technology; $b$ - using electric-pulse effect at optimum mode field [6-8]. Effect of shock waves provides for rise of particle rate, and reduction of deviation from average diameter related with fragmentation results in decrease of velocity spread. All this provides denser and more uniform package of particles in the coating, its strength increases and porosity reduces.

Tests on coating-to-base adhesion strength and wear resistance were carried out for determination of service properties of the coatings.

Coating-to-base adhesion strength was determined using the method of «pulling of tapered pin». Specimens for determination of adhesion strength were manufactured from quality structural carbon steel 45. The coatings before deposition were degreased by technical ethanol and subjected to jet-abrasive machining. Thickness of the deposited coatings made $0.6 \mathrm{~mm}$. Spraying was carried out using the modes mentioned above. Five specimens were used for one pass spraying at one mode in order to receive the results of coating-to-base adhesion strength. Five parallel tests each were performed for each mode. Figure 3 shows the results of determination of coating-to-base adhesion strength.

Thus, piling-up of high-voltage electric pulses of $5 \mathrm{kV}$ amplitude and $6.5 \mathrm{kHz}$ frequency on DHTF provides for $30 \%$ rise of adhesion strength of electric-arc steel coating and $20 \%$ of bronze plasma one. Increase of adhesion strength of received coatings can be explained through rise of their rate due to fragmentation as well as effect of the shock waves, that provides for larger real area of particle-to-base contact.

Wear resistance of electric-arc coatings was determined on roller-shoe scheme (Figure $4, a$ ) in limited supply of lubrication at 30 drops per minute rate. Engine oil of M10G2K GOST 8581- 
75 grade was used as lubrication. Circumferential speed of rotation of the roller made $0.8 \mathrm{~m} / \mathrm{s}$, pressure $4 \mathrm{MPa}$. Measurements of weight loss were carried out after breaking-in on TBE- 0.21 scales after each $10 \mathrm{~km}$ of pass. In total there were ten measurements each.

Shoe and roller were also manufactured from steel 45. Electric-arc coating was deposited on the roller after degreasing and jet-abrasive machining. The shoe was subjected to heat improvement, i.e. quenching was carried out from $840{ }^{\circ} \mathrm{C}$ for $50 \mathrm{~min}$ and cooling in water. Hardness after quenching made $H R C$ 54-55. Further, tempering was carried out at $550{ }^{\circ} \mathrm{C}$ for $1 \mathrm{~h}$ and cooling in air. Hardness after tempering made HRC 30-32.

Analysis of the results on evaluation of wear resistance (Figure 4, $b$ ) showed that electric-arc coating, deposited using high-voltage electric pulses, has 1.7 times lower wear than coating sprayed using traditional technology.

Analysis of friction surface of the coatings showed that mechanochemical wear-out is typical for studied specimens under set conditions. It is accompanied by formation on the surface of mating pair of films, enriched by oxygen (Figure 5).

Friction surface of the roller, sprayed with pile-up of electric pulses (Figure $5, b$ ) is denser and has porosity 2 times lower than the coating sprayed on traditional technology (Figure $5, a$ ). Figure $5, b$ shows friction traces of small depth which have more uniform arrangement over friction surface, that results in lower wear-out.

It should be noted that price of source for generation of high-voltage electric pulses makes approximately $5 \%$ of cost, for example, of equipment for electric-arc spraying. At that, effect of its application can provide producing of the coat- ings with service properties increased on average by $30 \%$.

\section{Conclusions}

Using of electric-pulse effect on DHTF in electric-arc and plasma spraying of coatings allows reducing size of metal drops in double-phase flow and receiving denser structure of plasma coating from powder PG-19M-01 and electric-arc coating from wire $\mathrm{Sv}-08 \mathrm{G} 2 \mathrm{~S}$. Determined are the optimum parameters of electric-arc effect in plasma and electric-arc spraying of the coating, which provide rise of adhesion strength by $18-30 \%$, hardness by $20-35 \%$, respectively, and wear resistance of electric-arc coating in 1.7 times.

1. Gutman, B.E. (1988) Drop refinement in plasma spraying with current modulation. Avtomatich. Svarka, 9, 37-39.

2. Kadyrmetov, A.M. (2012) Study of processes of plasma spraying and strengthening of coatings and ways of their quality control. Nauchny Zhurnal Kub$G A U, 81,1-18$.

3. Korotkikh, V.M. (2011) Controlled energy-saving technologies of plasma spraying of protective coatings for agricultural purpose. Vestnik AltajGAU, 82(8), 83-87.

4. Galyshkin, N.V., Korotkikh, V.M. Unit for plasma spraying. Pat. 2335347 Russia. Int. Cl. B05B7/22. Fil. 09.01.2007.

5. Adler, Yu.P., Markova, E.V., Granovsky, Yu.V. (1976) Planning of experiment in search of optimal conditions. Moscow: Nauka.

6. Grigoriev, A.I. (2000) Electrodispersion of liquid in realization of oscillating instability of its free surface. Zhurnal Tekhn. Fiziki, Vol. 70, Issue 5, 22-27.

7. Grigoriev, A.I. (2000) Capillary electrostatic instabilities. Sorovsky Obraz. Zhurnal, Vol. 6, Issue 6, 37-43.

8. Grigoriev, A.I. (2009) Electrostatic instability of highly-charged spray of conducting liquid. Zhurnal Tekhn. Fiziki, Vol. 79, Issue 4, 36-45.

Received 24.10.2014 